Article type : Meta-analysis

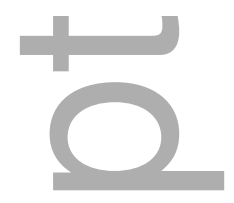

Text: 2,325 words Abstract: 200 words

Tables: 3

Figure: 1

Supplemental Figure: 1

$\mathbf{N}$-acetylcysteine for major mental disorders: a systematic review and meta-analysis of randomized controlled trials

Running title: $\mathrm{N}$-acetylcysteine for major mental disorders

${ }^{\# 1}$ Wei Zheng, MD;

\#2Qing-E Zhang, MD;

\# ${ }^{3}$ Dong-Bin Cai, MD;

${ }^{1}$ Xin-Hu Yang, MD;

${ }^{1}$ Yun Qiu, MD;

${ }^{4}$ Gabor S. Ungvari, MD, PhD;

${ }^{5}$ Chee H. Ng, MBBS, MD;

${ }^{6,7}$ Michael Berk, MD, PhD

${ }^{1 *}$ Yu-Ping Ning, MD, PhD;

${ }^{8 *}$ Yu-Tao Xiang, MD, PhD

1. The Affiliated Brain Hospital of Guangzhou Medical University (Guangzhou Huiai Hospital), Guangzhou, China;

2. The National Clinical Research Center for Mental Disorders \& Beijing Key Laboratory of Mental Disorders, Beijing Anding Hospital, Capital Medical University, Beijing, China;

3. Clinics of Chinese Medicine, the First Clinical Medical College of Guangzhou

This is the author manuscript accepted for publication and has undergone full peer review but has not been through the copyediting, typesetting, pagination and proofreading process, which may lead to differences between this version and the Version of Record. Please cite this article as doi:

10.1111/acps.12862

This article is protected by copyright. All rights reserved 
University of Chinese Medicine, Guangzhou, China;

4. The University of Notre Dame Australia / Graylands Hospital, Perth, Australia;

5. Department of Psychiatry, University of Melbourne, Melbourne, Victoria, Australia;

6. Deakin University, School of Medicine, IMPACT Strategic Research Centre, Barwon Health, Geelong, Victoria, Australia.

7. Orygen, The Centre of Excellence in Youth Mental Health, the Department of Psychiatry and the Florey Institute of Neuroscience and Mental Health, The University of Melbourne, Australia.

8. Unit of Psychiatry, Faculty of Health Sciences, University of Macau, Macao SAR, China

"These authors contributed equally to this review.

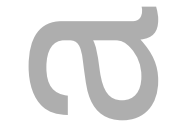

* Address correspondence to Dr. Yu-Tao Xiang, 3/F, Building E12, Faculty of Health Sciences, University of Macau, Avenida da Universidade, Taipa, Macau SAR, China. Fax: +853-2288-2314; Phone: +853-8822-4223; E-mail: xyutly@gmail.com; or Dr. Yu-Ping Ning, the Affiliated Brain Hospital of Guangzhou Medical University (Guangzhou Huiai Hospital), Guangzhou, China; Fax: +86-20-81891425. Telephone: +86-18510808443. E-mail: ningjeny@126.com

\section{Conflict of interest}

The authors declare that they have no conflicts of interest concerning this paper.

\section{Acknow ledgements}

The study was supported by the University of Macau (MYRG2015-00230-FHS; MYRG2016-00005-FHS) and the Affiliated Brain Hospital of Guangzhou Medical University (2016YFC0906302; 2014Y2-00105; 2015BAl 13B02). MB is supported This article is protected by copyright. All rights reserved 
by a National Health and Medical Research Council (NHMRC) Senior Principal Research Fellowship (grant number 1059660).

\begin{abstract}
Objective: This systematic review and meta-analysis of randomized controlled trials (RCTs) examined the efficacy and safety of adjunctive $\mathrm{N}$-Acetylcysteine (NAC), an antioxidant drug, in treating major depressive disorder (MDD), bipolar disorder, and schizophrenia.
\end{abstract}

Methods: The PubMed, Cochrane Library, PsyclNFO, CNKI, CBM and WanFang databases were independently searched and screened by two researchers. Standardized mean differences (SMDs), risk ratio and their $95 \%$ confidence intervals (Cls) were computed.

Results: Six RCTs $(n=701)$ of NAC for schizophrenia ( 3 RCTs, $n=307$ ), bipolar disorder ( 2 RCTs, $n=125$ ), and MDD ( 1 RCT, $n=269$ ) were identified and analyzed as separate groups. Adjunctive NAC significantly improved total psychopathology $\left(\mathrm{SMD}=-0.74,95 \% \mathrm{Cl}:-1.43,-0.06 ; \mathrm{I}^{2}=84 \%, \mathrm{P}=0.03\right)$ in schizophrenia, but it had no significant effect on depressive and manic symptoms as assessed by the Young Mania Rating Scale in bipolar disorder, and only a small effect on major depressive symptoms. Adverse drug reactions to NAC and discontinuation rates between the NAC and control groups were similar across the three disorders.

Conclusions: Adjunctive NAC appears to be a safe treatment that has efficacy for schizophrenia, but not for bipolar disorder or MDD. Further higher quality RCTs are warranted to determine the role of adjunctive NAC in the treatment of major psychiatric disorders.

Review registration: PROSPERO: CRD42017076524

Key words: N-Acetylcysteine; oxidative stress; schizophrenia; bipolar disorder; major depressive disorder

\title{
Significant outcomes
}

- Oxidative stress is implicated in the etiopathogenesis of schizophrenia, bipolar disorder, and major depressive disorder. 
- Results of randomized controlled trials (RCTs) on the efficacy of adjunctive $\mathrm{N}$-Acetylcysteine (NAC) in these disorders have been mixed.

- Adjunctive NAC appears to be an efficacious treatment for schizophrenia, but not for bipolar disorder or major depressive disorder.

\section{Limitations}

- The number of RCTs on each of the three disorders is relatively small.

- Only physically healthy patients were recruited in the RCTs, which lim its the generalizability of the findings.

\section{Introduction}

Mental and substance-use disorders account for $7.4 \%$ of all disability-adjusted life years (DALYs) worldwide (1), surpassing both cancer and cardiovascular diseases (2). Major mental disorders, i.e., major depressive disorder (MDD), bipolar disorder, and schizophrenia, account for $40.5 \%, 7.4 \%$ and $7.0 \%$ of DALYs, respectively among all mental and substance-use disorders (1). Apart from the heavy socioeconomic burden, major mental disorders are significantly associated with increased mortality (3-5). The response and remission rates of major mental disorders to pharmacotherapy, however, remain unsatisfactory (6).

Over the past years, the association of oxidative stress with neuropsychiatric disorders, especially major mental disorders, has received increased attention ( 7 , 8). Certain antidepressants (such as escitalopram) (9,10), antipsychotics (such as olanzapine and clozapine) $(11,12)$ and mood stabilizers (such as lithium and valproate) $(13,14)$ show intrinsic antioxidant properties, while antioxidant drugs (such as celecoxib) $(15,16)$ have shown potential in treating major mental disorders.

Glutathione is an endogenous antioxidant in the brain (17). As a redox scavenger, glutathione carries a free thiol group that could maintain the oxidative status of key cellular enzymes (18). Moreover, the cycle of glutathione and the reduced species glutathione disulphide play an important role in regulating This article is protected by copyright. All rights reserved 
cellular oxidative balance (18). N-Acetylcysteine (NAC), as the precursor of glutathione, has antioxidant, anti-inflammatory and neuroprotective properties which could modulate dopaminergic and glutamatergic systems (19). In regard to clinical utility, NAC has shown sufficient bioavailability (20).

NAC has the capacity to reverse oxidative stress induced by mitochondrial dysfunction $(21,22)$, and also contributes to the regulation of oxidative balance by the actions of the cysteine and cystine cycle (18). Similar to glutathione, cysteine and cystine are coupled redox partners that could alleviate oxidative cellular dysfunction and injury $(23,24)$. Pathological levels of oxidative stress have been found in schizophrenia (25), bipolar disorder (26), and MDD (27). However, results of randomized controlled trials (RCTs) (28-33) on the efficacy of adjunctive NAC in these disorders have been mixed. Previously meta-analyses have narrowly focused on a single disorder (i.e. schizophrenia (34) or certain symptomatology (i.e. depressive symptoms (35).

\section{Aims of the study}

In order to investigate the broader evidence, a systematic review and meta-analysis of randomized controlled trials was conducted to examine the efficacy and safety of adjunctive NAC in major mental disorders, namely in schizophrenia, bipolar disorder and MDD separately.

\section{Methods}

This meta-analysis was conducted according to both the Cochrane Collaboration (36) and the Preferred Reporting Items for Systematic Reviews and Meta-Analyses (PRISMA) guidelines (37).

\section{Literature search strategy}

In order to identify the relevant RCTs, a thorough literature search was independently conducted by two authors ( $W Z$ and $D-B C$ ) scrutinizing the PubMed, Cochrane Library, and PsycINFO, CNKI, CBM, and WanFang databases from their respective inception date to September 10, 2017. Following the methodology of another meta-analysis (35), the following search terms were used: [("depression" OR "depressive" OR "depressed") OR ("bipolar disorder" OR This article is protected by copyright. All rights reserved 
"bipolar depression" OR "manic depressive" OR "bipolar affective psychosis" OR "manic depression" OR "bipolar affective" OR "manic state" OR "mania" OR "manic" OR "manic disorder" OR "bipolar psychosis") OR ("schizophrenic disorder" OR "disorder, schizophrenic" OR "schizophrenia" or "dementia praecox" OR "psychosis" OR "mental disorder" OR "mental illness" OR "psychiatric disorder")] AND (NAC OR "N-acetylcysteine" OR "acetylcysteine") AND ("trial* " OR "control" OR"random*"). Additionally, references of included RCTs (28-33) as well as previous reviews and meta-analyses $(34,35)$ were searched manually for RCTs that may have been missed in the electronic search.

\section{I nclusion criteria}

The inclusion criteria were presented in accordance with the PICOS strategy: Participants: adult patients with schizophrenia, bipolar disorder, or MDD according to any diagnostic criteria and in acute phase of the illness. Intervention vs. Comparison: adjunctive NAC vs. control groups. Outcomes: the primary outcome measure was clinical efficacy as defined by the respective studies. Key secondary outcomes included any cause discontinuation rate and adverse drug reactions (ADRs). Study design: all published RCTs, with meta-analyzable data (i.e., mean and its standard deviation (SD) or $95 \%$ confidence intervals ( $\mathrm{Cls}$ ) for continuous outcome measures).

\section{Data extraction}

Three investigators ( $X-H Y, Y Q$ and $D-B C$ ) independently extracted data from the included RCTs. Data from trials with intention-to-treat (ITT) or modified ITT analysis were preferred over data on observed cases (OC) in instances where both were available. Discrepancies in data extraction were resolved by a discussion leading to a consensus between the three investigators ( $X-H Y, Y Q$ and $D-B C)$. When the relevant information was not available from the publications, the corresponding authors of included RCTs were contacted. For example, the relevant data were not available in three studies (28-30). Upon request, the authors provided the relevant data. Whenever multiple reports with overlapping data were identified, only the study with complete dataset was included. 


\section{Data synthesis and statistical analyses}

The RevMan software (version 5.3) (http://www.cochrane.org) was used for all meta-analyzable data using the random effects model (38). Standardized mean differences (SMDs) were used to assess continuous outcomes. For dichotomous outcomes, the absolute number of events were extracted and the risk ratio (RR) were estimated. The $95 \% \mathrm{Cl}$ s of SMD and RR were also calculated.

The heterogeneity between RCTs was examined using the $Q$ test or $1^{2}$ statistics, with $P$ value $<0.1$ in $Q$ test and $I^{2} \geq 50 \%$ considered as significant heterogeneity (39). In case of $\mathrm{I}^{2} \geq 50 \%$ for the primary outcome, sensitivity, subgroup, or meta-regression analyses were conducted to detect the source of the heterogeneity. The level of significance for all outcomes was set at 0.05 (two-sided).

\section{Quality Assessment}

The methodological quality of RCTs was assessed independently by three investigators (X-HY, YQ and D-BC) using the Cochrane risk of bias (36) and the Jadad scale (40); the Jadad total score of less than 3 was rated as low quality, otherwise it was considered high quality (40). The overall evidence level was assessed using the grading of recommendations assessment, development, and evaluation (GRADE) system $(41,42)$.

\section{Results}

\section{Literature search}

The electronic search yielded altogether 534 hits (Figure 1). After removing duplicate articles (104 studies), and reviewing the titles or abstracts (411 studies) and full texts (13 studies), 6 RCTs (28-33) met the inclusion criteria and were analyzed.

\section{The characteristics of studies in the meta-analysis}

The 6 RCTs with a total of 701 subjects (schizophrenia: 3 RCTs, $n=307$; bipolar disorder: 2 RCTs, $n=125$; major depression: $1 \mathrm{RCT}, \mathrm{n}=269$ ) compared the NAC groups (1.2-6 g/day) with control groups. Only physically healthy patients were recruited in included RCTs.

This article is protected by copyright. All rights reserved 
Schizophrenia: all the 3 RCTs were double-blinded and 2 (66.7\%) used ITT analyses. The weighted mean age was 34.9 years, mean illness duration was 6.8 years, and $59.6 \%$ of the subjects were males (Table 1). The fixed dosage of NAC was $2000 \mathrm{mg} /$ day in $2 \mathrm{RCTs}$ and $6000 \mathrm{mg} /$ day in $1 \mathrm{RCT}$ (Table 1).

Bipolar disorder: 1 RCT (50\%) were double-blinded and all the 2 studies used ITT analyses. The weighted mean age was 39.2 years, mean illness duration was 6.5 years, and $36.0 \%$ of the subjects were males (Table 1). The fixed dosage of NAC was $1200 \mathrm{mg} /$ day in $1 \mathrm{RCT}$ and $2000 \mathrm{mg} /$ day in another RCT (Table 1).

Major depressive disorder: Only one double-blinded RCT with ITT analyses was found. The mean age was 50.2 years, mean illness duration was 25 years, and $36.9 \%$ of the subjects were males (Table 1). The fixed dosage of NAC was 2000 mg/day (Table 1).

\section{Assessment of quality}

Five of the $6(83.3 \%)$ RCTs $(28-31,33)$ were double blinded and only one (32) was open label. Further, 4 (66.7\%) RCTs (28-31) described the random allocation sequence generation and allocation concealment methods (Supplemental Figure 1). Incomplete outcome data were rated as low risk (e.g. applied to ITT or modified ITT analysis) in all RCTs, while selective reporting was rated as low risk in 4 (66.7\%) RTCs (28-31). Overall, the mean Jadad score was 4.2 (range=2-5) (Table 1); 5 RCTs (83.3\%) was rated as high quality (Jadad score $\geqslant 3$ ). The overall evidence quality of 23 meta-analytic outcomes using the GRADE approach ranged from "low" (21.7\%), to "moderate" (73.9\%) and "high" (4.4\%) (Table 2).

\section{Primary and secondary outcomes}

Schizophrenia: three RCTs $(28,31,33)$ examined the efficacy and safety of adjunctive NAC in subjects who were assessed with the Positive and Negative Syndrome Scale (PANSS) (43). NAC showed significant superiority over placebo in improving total psychopathology $\left(\mathrm{SMD}=-0.74,95 \% \mathrm{Cl}:-1.43,-0.06 ; \mathrm{I}^{2}=84 \%\right.$, $\mathrm{P}=0.03$, Table 3 ), but not in positive, negative, or general psychopathology This article is protected by copyright. All rights reserved 
scales of the PANSS $\left(S M D=-0.59\right.$ to $-0.16,95 \% \mathrm{Cl}:-2.00,0.29 ; \mathrm{I}^{2}=59 \%$ to $93 \%$, $\mathrm{P}=0.08$ to 0.48 , Table 3 ).

Discontinuation rates were similar between the NAC and placebo groups $(\mathrm{RR}=0.96,95 \% \mathrm{Cl}: 0.65,1.43 ; \mathrm{P}=0.84$, Table 3$)$. Meta-analyses of ADRs including drowsiness, headache, constipation, diarrhea, and nausea ( $R R=0.83$ to $1.79,95 \% \mathrm{Cl}: 0.48,4.79 ; \mathrm{I}^{2}=0 \%$ to $29 \%, \mathrm{P}=0.14$ to 0.83 , Table 3 ) did not show group differences. One study (33) found that NAC was associated with improvement in lipid metabolic dysregulation, but not in body weight.

Bipolar disorder: two RCTs $(29,32)$ examined the efficacy and safety of adjunctive NAC for bipolar disorder. There were no significant group differences with respect to depressive sym ptoms ( $2 \mathrm{RCTs}, \mathrm{n}=124$; $\mathrm{SMD}=-0.59,95 \% \mathrm{Cl}:-1.48$, $0.30 ; I^{2}=83 \%, P=0.19$ ) as rated by the Montgomery and Asberg Depression Rating Scale (MADRS) (1 RCT) and the Hamilton Depression Rating Scale (1 $\mathrm{RCT}$ ), and manic symptoms as rated by the Young Mania Rating Scale (YMRS) (Table 3). Discontinuation rate was similar between the NAC and placebo groups $(R R=1.22,95 \% \mathrm{Cl}: 0.66,2.24 ; \mathrm{P}=0.53$, Table 2$)$. No group differences in treatment emergent adverse events were found.

Major depressive disorder: one RCT (30) examined the efficacy and safety of adjunctive NAC for MDD as measured by the MADRS. Although no significant group difference was found in the primary outcome, the results showed a positive trend for adjunctive NAC, particularly for subjects with higher MADRS score. Discontinuation rate was similar between the NAC and placebo groups. No group differences regarding ADRs were observed except that the NAC group had more frequent gastrointestinal $(33.9 \%$ vs. $18.4 \% ; p=0.005)$ and musculoskeletal complaints $(3.9 \%$ vs. $0 \% ; P=0.025)$.

\section{Publication bias}

Publication bias for the outcomes could not be examined by a funnel plot graph or the Egger's test (44)as the number of RCTs in the meta-analysis was less than 10.

This article is protected by copyright. All rights reserved 


\section{Discussion}

This systematic review and meta-analysis examined the efficacy and safety of adjunctive NAC across three major psychiatric disorders. The findings appear to support the efficacy of adjunctive NAC for schizophrenia, but not for bipolar disorder or MDD. The reasons for the differential efficacy of NAC in the three disorders are unclear and warrant further studies. The use of other anti-oxidants or anti-inflammatory agents might mix the efficacy of NAC for major psychiatric disorders, but inadequate data were reported in included studies. The findings of the current study are supported by a previous case report (45), but not with the other case report (46) or observational study (47). Specifically, Bulut et al. (45) found NAC augmentation beneficial in a patient with treatment resistant schizophrenia, while Carvalho et al. (48) reported that two patients with treatment-resistant MDD had sustained improvement after adjunctive NAC was added to tranylcypromine. In an 8-week open-label study that included 149 patients with recent bipolar depressive episodes, adjunctive NAC resulted in robust improvement in depressive symptoms, functioning and quality of life (47).

Evidence for dysregulated oxidative signaling in many neuropsychiatric disorders is accumulating. For example, biomarkers of oxidative damage in the central nervous system have been found in subjects with bipolar disorder, depression and schizophrenia (49-51). Dysregulation of mitochondria (52) and genetically mediated mitochondrial disorders (53) have also been observed in major psychiatric disorders. Amrouche-Mekkioui and Djerdjouri (54) found that NAC could improve redox status and mitochondrial dysfunction, which may be related to its efficacy in treating major psychiatric disorders.

Deregulated inflammatory pathways and aberrant blood cytokine levels, such as pro- and anti-inflammatory cytokines, are also thought to play a role in the pathophysiology of major mental disorders (55). Hence, the potential therapeutic mechanism of NAC in treating major psychiatric disorders could be related to its anti-inflam matory properties (18). NAC inhibits the expression and secretion of interleukin (IL)-10 and inflammatory cytokines (e.g., IL-1 $\beta$ and IL-6) in LPS-activated macrophagecell lines under mild oxidative conditions (56), which, in turn, could be responsible for its therapeutic effect in major psychiatric disorders. Although NAC appears to be safe, it may induce gastrointestinal and This article is protected by copyright. All rights reserved 
musculoskeletal ADRs in patients with MDD (30). Idiosyncratic adverse reactions, such as asthma and pulmonary hypertension, have been reported in animal, but not in human studies (57). In addition to the major psychiatric disorders discussed so far, NAC has also shown to have efficacy in other psychiatric disorders, such as substance use disorders (58) and obsessive-compulsive disorder (OCD) (59). Furthermore, NAC is routinely used for treatment of Paracetamol poisoning $(9,11)$.

This meta-analysis of adjunctive NAC for major psychiatric disorders is more comprehensive than a previous meta-analysis (35) that included 5 RCTs ( $n=574$ ) exploring depressive symptoms. The previous study (35) found that NAC ameliorated depressive symptoms in diverse diagnostic groups, which is not consistent with findings of our study which only included people with MDD. The Fernandes study (35) also included tobacco use disorder (60) and trichotillomania (61), hence explored a heterogeneous sample. Our meta-analysis also applied quality assessment by using the Jadad scale, and the overall evidence level using GRADE approach.

The findings of this study should be interpreted with caution due to the following methodological limitations. First, the number of RCTs of the three major psychiatric disorders were relatively small, precluding subgroup and sensitivity analyses. For the same reason, the relationship between efficacy and doses and treatment duration could not be adequately examined. Second, it is unclear whether all the included studies had restricted the use of other anti-oxidants or anti-inflammatory agents, although most did. Finally, only physically healthy patients were recruited in included RCTs, which limits the generalizability of the findings.

\section{Conclusion}

Adjunctive NAC appears to be a safe treatment that has efficacy in schizophrenia but not in bipolar disorder or MDD. The benefits of adjunctive NAC in major psychotic and mood disorders warrants further investigations together with its long-term effects and safety.

\section{References}

This article is protected by copyright. All rights reserved 
1. Whiteford HA, Degenhardt L, Rehm J, et al. Global burden of disease attributable to mental and substance use disorders: findings from the Global Burden of Disease Study 2010. Lancet 2013; 382:1575-1586.

2. Mathers C, Boerma JT, Fat DM, Organization WH. The global burden of disease: 2004 update. published by the Harvard School of Public Health on behalf of the World Health Organization and the World Bank :, 2008

3. Chesney E, Goodwin GM, Fazel S. Risks of all-cause and suicide mortality in mental disorders: a meta-review. World Psychiatry 2014; 13:153-160.

4. Correll CU, Ng-Mak DS, Stafkey-Mailey D, Farrelly E, Rajagopalan K, Loebel A. Cardiometabolic comorbidities, readmission, and costs in schizophrenia and bipolar disorder: a real-world analysis. Annals of general psychiatry $2017 ; 16$ : 9 .

5. Correll CU, Solmi M, Veronese N, et al. Prevalence, incidence and mortality from cardiovascular disease in patients with pooled and specific severe mental illness: a large-scale meta-analysis of 3,211,768 patients and 113,383,368 controls. World Psychiatry 2017; 16:163-180.

6. Torrey EF, Davis JM. Adjunct treatments for schizophrenia and bipolar disorder: what to try when you are out of ideas. Clinical schizophrenia \& related psychoses 2012; 5:208-216.

7. Pawelczyk T, Grancow-Grabka M, Trafalska E, Szemraj J, Pawelczyk A. Oxidative stress reduction related to the efficacy of $n-3$ polyunsaturated fatty acids in first episode schizophrenia: Secondary outcome analysis of the OFFER randomized trial. Prostaglandins, leukotrienes, and essential fatty acids $2017 ; 121: 7-13$.

8. Flatow J, Buckley P, Miller BJ. Meta-analysis of oxidative stress in schizophrenia. Biological psychiatry 2013; 74:400-409.

9. Bailey GP, Wood DM, Archer JR, Rab E, Flanagan RJ, Dargan PI. An assessment of the variation in the concentration of acetylcysteine in infusions for the treatment of paracetamol overdose. British journal of clinical pharmacology 2017; 83:393-399.

10. Cumurcu BE, Ozyurt H, Etikan I, Demir S, Karlidag R. Total antioxidant capacity and total oxidant status in patients with major depression: impact of antidepressant treatment. Psychiatry \& Clinical Neurosciences 2009; This article is protected by copyright. All rights reserved 


\section{$63: 639-645$.}

11. Wong A, Landersdorfer C, Graudins A. Pharmacokinetic modelling of modified acetylcysteine infusion regimens used in the treatment of paracetamol poisoning. European journal of clinical pharmacology 2017; $73: 1103-1110$.

12. Zhang $X Y$, Tan $Y L$, Cao LY, et al. Antioxidant enzymes and lipid peroxidation in different forms of schizophrenia treated with typical and atypical antipsychotics. Schizophrenia Research 2006; $81: 291$.

13. Frey BN, Valvassori SS, Reus GZ, et al. Effects of lithium and valproate on amphetamine-induced oxidative stress generation in an animal model of mania. Journal of psychiatry \& neuroscience : JPN 2006; 31:326-332.

14. Shao L, Young LT, Wang J: The effect of the mood stabilizer valproate on the major brain antioxidant glutathione and functionally related enzymes in human neuroblastoma SH-SY5Y cells, in Convention of the Society-Of-Biological-Psychiatry, 2005, pp 19S-19S

15. Zheng $W$, Cai DB, Yang $X H$, et al. Adjunctive celecoxib for schizophrenia: $A$ meta-analysis of randomized, double-blind, placebo-controlled trials. Journal of psychiatric research 2017; $92: 139-146$.

16. Magalhaes PV, Dean O, Andreazza AC, Berk M, Kapczinski F. Antioxidant treatments for schizophrenia. The Cochrane database of systematic reviews $2016 ; 2$ : CD008919.

17. Dringen R, Hirrlinger J. Glutathione pathways in the brain. Biological chem istry 2003; 384:505-516.

18. Berk M, Malhi GS, Gray LJ, Dean OM. The promise of N-acetylcysteine in neuropsychiatry. Trends Pharmacol. Sci. 2013; 34:167-177.

19. Dean O, Giorlando F, Berk M. N-acetylcysteine in psychiatry: current therapeutic evidence and potential mechanisms of action. Journal of psychiatry \& neuroscience : JPN 2011; 36:78-86.

20. Holdiness MR. Clinical pharmacokinetics of $\mathrm{N}$-acetylcysteine. Clinical pharmacokinetics $1991 ; 20: 123-134$.

21. Wang CC, Fang KM, Yang CS, Tzeng SF. Reactive oxygen species-induced cell death of rat primary astrocytes through mitochondria-mediated mechanism. Journal of cellular biochemistry 2009; 107:933-943.

This article is protected by copyright. All rights reserved 
22. Otte DM, Sommersberg B, Kudin A, et al. N-acetyl cysteine treatment rescues cognitive deficits induced by mitochondrial dysfunction in G72/G30 transgenic mice. Neuropsychopharmacology : official publication of the American College of Neuropsychopharmacology 2011; 36:2233-2243.

23. Iyer SS, Jones DP, Brigham KL, Rojas M. Oxidation of plasma cysteine/cystine redox state in endotoxin-induced lung injury. American journal of respiratory cell and molecular biology 2009; 40:90-98.

24. Banjac A, Perisic T, Sato $\mathrm{H}$, et al. The cystine/cysteine cycle: a redox cycle regulating susceptibility versus resistance to cell death. Oncogene 2008; 27:1618-1628.

25. Ciobica A, Padurariu M, Dobrin I, Stefanescu C, Dobrin R. Oxidative stress in schizophrenia - focusing on the main markers. Psychiatria Danubina 2011; $23: 237-245$.

26. Scola G, Andreazza AC. Oxidative Stress in Bipolar Disorder. Springer New York, 2015

27. Stefanescu C, Ciobica A. The relevance of oxidative stress status in first episode and recurrent depression. Journal of Affective Disorders 2012; 143:34-38.

28. Berk $\mathrm{M}$, Copolov D, Dean $\mathrm{O}$, et al. $\mathrm{N}$-acetyl cysteine as a glutathione precursor for schizophrenia--a double-blind, randomized, placebo-controlled trial. Biol. Psychiatry 2008; 64:361-368.

29. Berk M, Copolov DL, Dean O, et al. N-acetyl cysteine for depressive symptoms in bipolar disorder--a double-blind randomized placebo-controlled trial. Biol. Psychiatry 2008; 64:468-475.

30. Berk M, Dean OM, Cotton SM, et al. The efficacy of adjunctive $\mathrm{N}$-acetylcysteine in major depressive disorder: a double-blind, randomized, placebo-controlled trial. J. Clin. Psychiatry 2014; 75:628-636.

31. Farokhnia M, Azarkolah A, Adinehfar F, et al. $\mathrm{N}$-acetylcysteine as an adjunct to risperidone for treatment of negative symptoms in patients with chronic schizophrenia: a randomized, double-blind, placebo-controlled study. Clin. Neuropharmacol. 2013; 36:185-192.

32. Hu CC, Xie J. N-acetylcysteine add on treatment for depressive symptoms in bipolar disorder:a comparative trial (in Chinese). Clinical Education of This article is protected by copyright. All rights reserved 
General Practice 2012; 10:515-517.

33. Zhang JH, Chen B, Lu JR. Treatment effect of risperidone alone and combined with $\mathrm{N}$-acetly-cysteine for first-episode schizophenic patients (in Chinese). J. Clin. Psychiatry 2015:394-396.

34. Chen AT, Chibnall JT, Nasrallah HA. Placebo-controlled augmentation trials of the antioxidant NAC in schizophrenia: A review. Annals of clinical psychiatry : official journal of the American Academy of Clinical Psychiatrists 2016; 28:190-196.

35. Fernandes BS, Dean OM, Dodd S, Malhi GS, Berk M. N-Acetylcysteine in depressive symptoms and functionality: a systematic review and meta-analysis. J. Clin. Psychiatry 2016; 77 :e457-466.

36. Higgins J, Higgins J. Cochrane handbook for systematic reviews of interventions. Ltd: Chichester, UK, John Wiley \& Sons, 2008

37. Moher D, Liberati A, Tetzlaff J, Altman DG. Preferred reporting items for systematic reviews and meta-analyses: the PRISMA statement. Ann. Intern. Med. 2009; 151:264-269, w264.

38. DerSimonian R, Laird N. Meta-analysis in clinical trials. Control. Clin. Trials $1986 ; 7: 177-188$.

39. Higgins JP, Thompson SG. Quantifying heterogeneity in a meta-analysis. Statistics in medicine 2002; $21: 1539-1558$.

40. Jadad AR, Moore RA, Carroll D, et al. Assessing the quality of reports of randomized clinical trials: is blinding necessary? Control. Clin. Trials 1996; $17: 1-12$.

41. Balshem $H$, Helfand $M$, Schunemann $H J$, et al. GRADE guidelines: 3 . Rating the quality of evidence. J. Clin. Epidemiol. 2011; 64:401-406.

42. Atkins D, Best D, Briss PA, et al. Grading quality of evidence and strength of recommendations. BMJ 2004; 328:1490.

43. Kay SR, Fiszbein A, Opler LA. The positive and negative syndrome scale (PANSS) for schizophrenia. Schizophr. Bull. 1987; 13:261-276.

44. Egger M, Davey Smith G, Schneider M, Minder C. Bias in meta-analysis detected by a simple, graphical test. BMJ 1997; 315:629-634.

45. Bulut M, Savas HA, Altindag A, Virit O, Dalkilic A. Beneficial effects of $\mathrm{N}$-acetylcysteine in treatment resistant schizophrenia. World $\mathrm{J}$ Biol This article is protected by copyright. All rights reserved 
Psychiatry 2009; 10:626-628.

46. Carvalho AF, Macedo DS, Goulia P, Hyphantis TN. N-acetylcysteine augmentation to tranylcyprom ine in treatment-resistant major depression. Journal of clinical psychopharmacology 2013; 33:719-720.

47. Berk M, Dean O, Cotton SM, et al. The efficacy of $\mathrm{N}$-acetylcysteine as an adjunctive treatment in bipolar depression: an open label trial. J. Affect. Disord. 2011; 135 :389-394.

48. Carvalho AF, Macedo DS, Goulia P, Hyphantis TN. N-acetylcysteine augmentation to tranylcyprom ine in treatment-resistant major depression. J. Clin. Psychopharmacol. 2013; 33:719-720.

49. Wang JF, Shao L, Sun X, Young LT. Increased oxidative stress in the anterior cingulate cortex of subjects with bipolar disorder and schizophrenia. Bipolar disorders 2009; 11:523-529.

50. Kunz M, Gama CS, Andreazza AC, et al. Elevated serum superoxide dismutase and thiobarbituric acid reactive substances in different phases of bipolar disorder and in schizophrenia. Progress in neuro-psychopharmacology \& biological psychiatry 2008; 32:1677-1681.

51. Liu T, Zhong S, Liao X, et al. A Meta-Analysis of Oxidative Stress Markers in Depression. PloS one 2015; 10 : e0138904.

52. Konradi C, Eaton M, MacDonald ML, Walsh J, Benes FM, Heckers S. Molecular evidence for mitochondrial dysfunction in bipolar disorder. Archives of general psychiatry 2004; 61:300-308.

53. Anglin RE, Garside SL, Tarnopolsky MA, Mazurek MF, Rosebush PI. The psychiatric manifestations of mitochondrial disorders: a case and review of the literature. The Journal of clinical psychiatry 2012; 73:506-512.

54. Amrouche-Mekkioui I, Djerdjouri B. N-acetylcysteine improves redox status, mitochondrial dysfunction, mucin-depleted crypts and epithelial hyperplasia in dextran sulfate sodium-induced oxidative colitis in mice. European journal of pharmacology 2012; 691:209-217.

55. Goldsmith DR, Rapaport MH, Miller BJ. A meta-analysis of blood cytokine network alterations in psychiatric patients: comparisons between schizophrenia, bipolar disorder and depression. Molecular psychiatry 2016; 21:1696-1709.

This article is protected by copyright. All rights reserved 
56. Palacio JR, Markert UR, Martinez P. Anti-inflammatory properties of $\mathrm{N}$-acetylcysteine on lipopolysaccharide-activated macrophages. Inflammation research : official journal of the European Histamine Research Society ... [et al.] 2011; 60:695-704.

57. Palmer LA, Doctor A, Chhabra $P$, et al. S-nitrosothiols signal hypoxia-mimetic vascular pathology. The Journal of clinical investigation 2007; 117:2592-2601.

58. Duailibi MS, Cordeiro Q, Brietzke E, et al. N-acetylcysteine in the treatment of craving in substance use disorders: Systematic review and meta-analysis. 2017; 26:660-666.

59. Oliver G, Dean O, Camfield D, et al. N-acetyl cysteine in the treatment of obsessive compulsive and related disorders: a systematic review. Clinical psychopharmacology and neuroscience : the official scientific journal of the Korean College of Neuropsychopharmacology 2015; 13:12-24.

60. Prado E, Maes M, Piccoli LG, et al. N-acetylcysteine for therapy-resistant tobacco use disorder: a pilot study. Redox report : communications in free radical-research 2015; $20: 215-222$.

61. Grant JE, Odlaug BL, Kim SW. N-acetylcysteine, a glutamate modulator, in the treatment of trichotillomania: a double-blind, placebo-controlled study. Arch. Gen. Psychiatry 2009; $66: 756-763$.

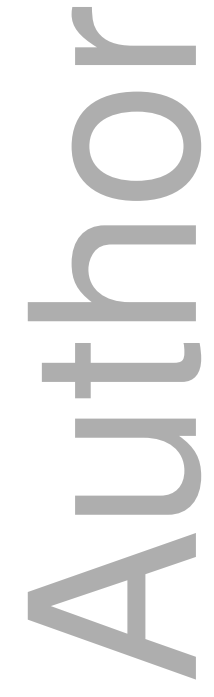

This article is protected by copyright. All rights reserved 
Table 1. Subject and treatment characteristics of the studies included in the meta-analysis

\begin{tabular}{|c|c|c|c|c|c|c|c|c|c|c|c|c|c|}
\hline $\begin{array}{l}\text { Study } \\
\text { (country) }\end{array}$ & $\begin{array}{l}\text { Number } \\
\text { of } \\
\text { patients }\end{array}$ & $\begin{array}{l}\text {-Blinding } \\
\text {-Analyses }\end{array}$ & $\begin{array}{l}\text { Trial } \\
\text { Duration } \\
(\text { wks })\end{array}$ & $\begin{array}{l}\text { Setting } \\
(\%)\end{array}$ & $\begin{array}{l}\text {-Diagnostic } \\
\text { criteria } \\
\text {-Diagnosis } \\
(\%)\end{array}$ & $\begin{array}{l}\text { Illness } \\
\text { duration } \\
(\mathbf{y r s})^{\mathrm{a}}\end{array}$ & $\begin{array}{l}\text { Age }^{\mathrm{a}}: \\
\text { yrs } \\
\text { (range) }\end{array}$ & $\begin{array}{l}\text { Sex }{ }^{\mathrm{a}}: \\
\text { Male } \\
(\%)\end{array}$ & $\begin{array}{l}\text { Control-Group } \\
\text { :Dose }(\mathrm{mg} / \mathrm{d}): \\
\text { mean }(\text { range })\end{array}$ & \multicolumn{2}{|c|}{$\begin{array}{l}\text { Intervention-Group: } \\
\text { Dose (mg/d): } \\
\text { mean (range) }\end{array}$} & $\begin{array}{l}\text { Jadad } \\
\text { score }\end{array}$ & Main finding \\
\hline \multicolumn{14}{|c|}{ Schizophrenia (3 RCTs, n=307) } \\
\hline $\begin{array}{l}\text { Berk } 2008 \\
\text { (multicenter) }\end{array}$ & $\begin{array}{l}\text { T: } 140 \\
\text { C: } 71 \\
\text { I: } 69\end{array}$ & -ITT & $24^{\mathrm{b}}$ & \begin{tabular}{|l|} 
In-(4) \\
and \\
Outpatien \\
ts (96)
\end{tabular} & $\begin{array}{l}\text {-DSM-IV } \\
\text {-SCZ (100) }\end{array}$ & 12.2 & $\begin{array}{c}36.6 \\
(18-65)\end{array}$ & 70.0 & $\begin{array}{l}\text { CPZ-equ: } \\
\varnothing=598\end{array}$ & $\begin{array}{l}\text { CPZ-equ: } \\
\varnothing=716\end{array}$ & $\begin{array}{l}\text { NAC: } \\
\varnothing=2000 \\
(\mathrm{FD})\end{array}$ & 5 & $\begin{array}{l}\text { NAC was more effective than placebo } \\
\text { in PANSS total, negative, general, } \\
\text { CGI-S and CGI-I scores. NAC was } \\
\text { associated with an improvement in } \\
\text { akathisia. }\end{array}$ \\
\hline $\begin{array}{l}\text { Farokhnia } \\
2013 \text { (Iran) }\end{array}$ & $\begin{array}{l}\text { T: } 46 \\
\text { C: } 23 \\
\text { I: } 23\end{array}$ & $\begin{array}{l}-\mathrm{DB} \\
-\mathrm{OC}\end{array}$ & 8 & \begin{tabular}{|l} 
Inpatients \\
$(100)$
\end{tabular} & $\begin{array}{l}\text {-DSM-IV-TR } \\
\text {-SCZ (100) }\end{array}$ & 7.2 & $\begin{array}{c}32.8 \\
(18-50)\end{array}$ & 47.6 & RIS: $\varnothing=4(2-6)$ & $\begin{array}{l}\text { RIS: } \\
\varnothing=4(2-6)\end{array}$ & $\begin{array}{l}\text { NAC: } \\
\varnothing=2000 \\
(1000-20 \\
00)\end{array}$ & 5 & $\begin{array}{l}\text { NAC group showed greater } \\
\text { improvement in the PANSS total and } \\
\text { negative subscale scores than placebo } \\
\text { group. }\end{array}$ \\
\hline $\begin{array}{l}\text { Zhang2015 } \\
\text { (China) }\end{array}$ & $\begin{array}{l}\text { T: } 121 \\
\text { C: } 60 \\
\text { I: } 61\end{array}$ & -DB & 8 & $\begin{array}{l}\text { In-(NR) } \\
\text { and } \\
\text { Outpatien } \\
\text { ts (NR) }\end{array}$ & $\begin{array}{l}- \text { ICD-10 } \\
-S C Z(100)\end{array}$ & 0.5 & $\begin{array}{c}33.9 \\
(18-50)\end{array}$ & 52.1 & $\begin{array}{ll}\text { RIS: } & \varnothing=\mathrm{NR} \\
(1-6) & \end{array}$ & $\begin{array}{l}\text { RIS: } \varnothing=N R \\
(1-6)\end{array}$ & $\begin{array}{l}\text { NAC: } \\
\varnothing=6000 \\
(\mathrm{FD})\end{array}$ & 3 & $\begin{array}{l}\text { NAC group showed greater } \\
\text { improvement in PANSS total, positive, } \\
\text { negative, and general symptom scores, } \\
\text { and also TG, LDL and TC. }\end{array}$ \\
\hline \multicolumn{14}{|c|}{ Bipolar disorder(2 RCTs, $n=125)$} \\
\hline $\begin{array}{l}\text { Berk } 2008 \\
\text { (Australia) }\end{array}$ & $\begin{array}{l}\text { T: } 75 \\
\text { C: } 37 \\
\text { I: } 38\end{array}$ & $\begin{array}{l}-\mathrm{DB} \\
-\mathrm{ITT}\end{array}$ & $24^{\mathrm{b}}$ & \begin{tabular}{|l} 
Outpatien \\
ts (100)
\end{tabular} & $\begin{array}{l}\text {-DSM-IV } \\
\text {-BP-I (81.3); } \\
\text { BP-II (18.7) }\end{array}$ & 10.3 & $\begin{array}{l}45.6 \\
(\mathrm{NR})\end{array}$ & 40.0 & $\begin{array}{l}\text { Medication }^{\mathrm{c}}: \\
\emptyset=\mathrm{NR}(\mathrm{NR})\end{array}$ & $\begin{array}{l}\text { Medication } \\
\text { c: } \quad \emptyset=\mathrm{NR} \\
(\mathrm{NR})\end{array}$ & $\begin{array}{l}\text { NAC: } \\
\emptyset=2000 \\
(\mathrm{FD})\end{array}$ & 5 & $\begin{array}{l}\text { NAC was associated with significant } \\
\text { improvement on the MADRS at } \\
\text { endpoint. }\end{array}$ \\
\hline $\begin{array}{l}\text { Hu } 2012 \\
\text { (China) }\end{array}$ & $\begin{array}{l}\text { T: } 50 \\
\text { C: } 22 \\
\text { I: } 28\end{array}$ & $\begin{array}{l}-\mathrm{OL} \\
-\mathrm{ITT}\end{array}$ & 10 & $\begin{array}{l}\text { In-(NR) } \\
\text { and } \\
\text { Outpatien } \\
\text { ts (NR) }\end{array}$ & $\begin{array}{l}\text {-CCMD-3 } \\
-\mathrm{BP}(100)\end{array}$ & 0.9 & $\begin{array}{c}29.7 \\
(15-61)\end{array}$ & 30.0 & $\begin{array}{l}\text { VPA-Na: } \varnothing=964 \\
(600-1200) ; \\
\text { PAR: } \varnothing=28 \\
(20-40)\end{array}$ & $\begin{array}{l}\text { VPA-Na: } \\
\emptyset=986 \\
(600-1200) ; \\
\text { PAR: } \varnothing=32\end{array}$ & $\begin{array}{l}\text { NAC: } \\
\varnothing=1200 \\
(\mathrm{FD})\end{array}$ & 2 & $\begin{array}{l}\text { NAC was associated with } \\
\text { improvement on depressive symptoms } \\
\text { assessed by the HAMD-17 and higher } \\
\text { remission rate. }\end{array}$ \\
\hline
\end{tabular}

This article is protected by copyright. All rights reserved 


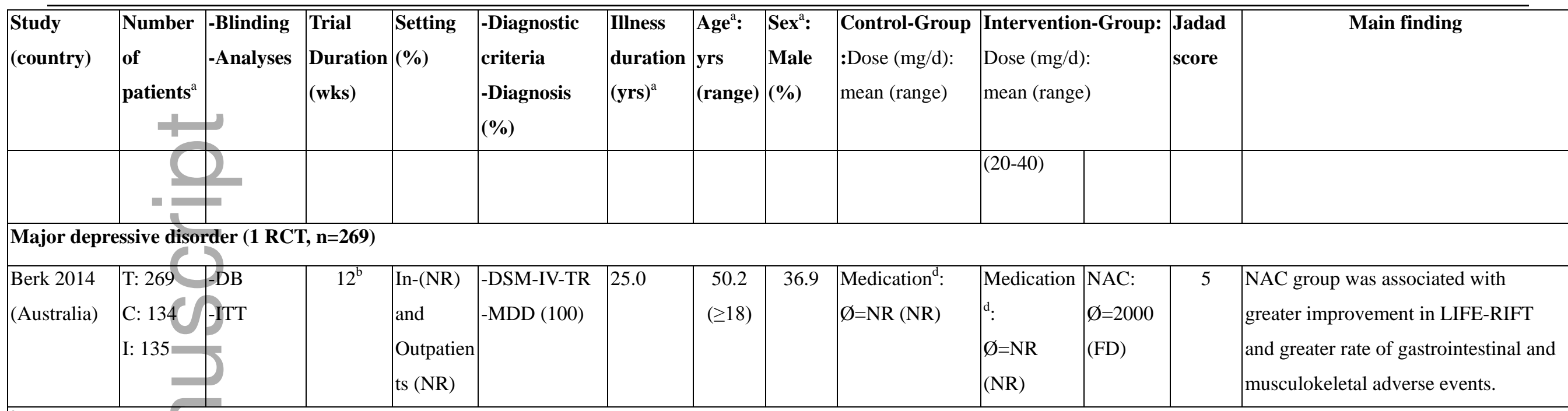

${ }^{\mathrm{a}}$ Data were extracted based on mean baseline value of each included trials.

${ }^{\mathrm{b}}$ A post discontinuation follow-up visit was conducted 4 weeks after the trial completion

'Including valproate, lithium, carbamazepine, lamotrigine, antipsychotics, antidepressants, benzodiazepines, and others.

${ }^{\mathrm{d}}$ No psychotropic medication, antidepressants, benzodiazepines, antipsychotics and mood stabilizer.

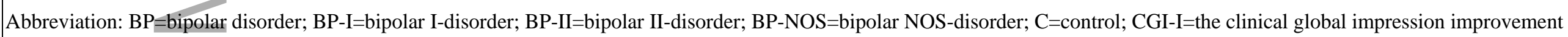

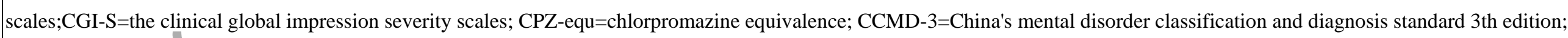

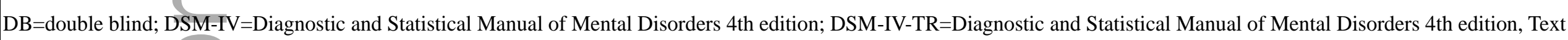

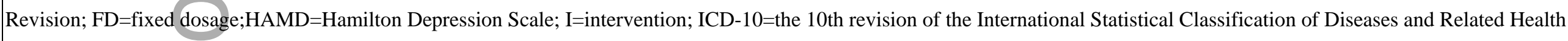
Problems; ITT=intent to treat; LDL=low density lipoprotein; LIFE-RIFT=The Longitudinal Interval Follow-Up Evaluation-Range of Impaired Functioning Tool;

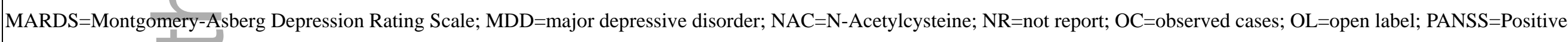

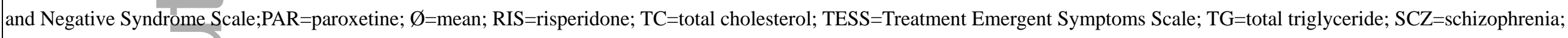
$\mathrm{T}=$ total; VPA-Na=Sodium valproate; wks=weeks; yrs=years.

Table 2. GRADE Analyses: N-acetylcysteine for major mental disorders

This article is protected by copyright. All rights reserved 


\begin{tabular}{|c|c|c|c|c|c|c|c|c|}
\hline $\begin{array}{l}\text { Primary and secondary } \\
\text { outcome }\end{array}$ & $\begin{array}{l}\text { Studies } \\
\text { (N) }\end{array}$ & $\begin{array}{c}\text { Risk } \\
\text { of bias }\end{array}$ & $\begin{array}{c}\text { Inconsiste } \\
\text { ncy }\end{array}$ & $\begin{array}{c}\text { Indirectne } \\
\text { ss }\end{array}$ & $\begin{array}{c}\text { Imprecisio } \\
\mathbf{n}\end{array}$ & $\begin{array}{l}\text { Publicatio } \\
\text { n bias }\end{array}$ & $\begin{array}{l}\text { Large } \\
\text { effect }\end{array}$ & $\begin{array}{l}\text { Overall quality of } \\
\text { evidence }^{a}\end{array}$ \\
\hline \multicolumn{9}{|l|}{ Schizophrenia } \\
\hline Total psychopathology & $3(247)$ & No & Serious $^{b}$ & No & No & Serious $^{\mathrm{c}}$ & No & $+/+/-/-/ ;$ Low \\
\hline Positive symptom scores & $3(247)$ & No & Serious $^{b}$ & No & No & Serious $^{\mathrm{C}}$ & No & $+/+/-/-/ ;$ Low \\
\hline Negative symptom scores & $3(247)$ & No & Serious $^{b}$ & No & No & Serious $^{\mathrm{C}}$ & No & +/+/-/-/; Low \\
\hline $\begin{array}{l}\text { General psychopathology scores } \\
\text { of the PANSS }\end{array}$ & $3(247)$ & No & Serious $^{b}$ & No & No & Serious $^{\mathrm{C}}$ & No & +/+/-/-/; Low \\
\hline Discontinuation for any reason & $3(307)$ & No & No & No & No & Serious $^{\mathrm{C}}$ & No & $+/+/+/-/ ;$ moderate \\
\hline Drowsiness & $2(167)$ & No & No & No & No & No & No & $+/+/+/+/ ;$ High \\
\hline Headache & $2(186)$ & No & No & No & No & Serious $^{\mathrm{c}}$ & No & $+/+/+/-/ ;$ moderate \\
\hline Constipation & $2(186)$ & No & No & No & No & Serious $^{c}$ & No & $+/+/+/-/ ;$ moderate \\
\hline Diarrhea & $2(186)$ & No & No & No & No & Serious $^{c}$ & No & $+/+/+/-/ ;$ moderate \\
\hline Nausea & $2(186)$ & No & No & No & No & Serious $^{c}$ & No & $+/+/+/ / / ;$ moderate \\
\hline \multicolumn{9}{|l|}{ Bipolar disorder } \\
\hline Depression scores & $2(124)$ & No & Serious $^{b}$ & No & No & Serious $^{\mathrm{C}}$ & No & +/+/-/-/; Low \\
\hline$B D R S$ & $1(74)$ & No & $\mathrm{N} / \mathrm{A}$ & No & No & Serious $^{c}$ & No & $+/+/+/-/ ;$ moderate \\
\hline CGI-S bipolar disorder & $1(74)$ & No & $\mathrm{N} / \mathrm{A}$ & No & No & Serious $^{c}$ & No & $+/+/+/-/ ;$ moderate \\
\hline CGI-S depression & $1(74)$ & No & $\mathrm{N} / \mathrm{A}$ & No & No & Serious $^{c}$ & No & $+/+/+/ / / ;$ moderate \\
\hline CGI-S mania & $1(74)$ & No & $\mathrm{N} / \mathrm{A}$ & No & No & Serious $^{\mathrm{C}}$ & No & $+/+/+/ / / ;$ moderate \\
\hline$G A F$ & $1(74)$ & No & $\mathrm{N} / \mathrm{A}$ & No & No & Serious $^{c}$ & No & $+/+/+/ / / ;$ moderate \\
\hline
\end{tabular}

This article is protected by copyright. All rights reserved 


\begin{tabular}{|c|c|c|c|c|c|c|c|c|}
\hline$\overline{L I F E-R I F T}$ & $101(74)$ & No & 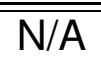 & No & No & Serious $^{\mathrm{C}}$ & $\overline{\mathrm{NNo}}$ & "+/+/+/-/; moderate \\
\hline$Q-L E S-Q$ & $1(74)$ & No & $\mathrm{N} / \mathrm{A}$ & No & No & Serious $^{c}$ & No & $+/+/+/-/ ;$ moderate \\
\hline SLICE/LIFE & $1(74)$ & No & $\mathrm{N} / \mathrm{A}$ & No & No & Serious $^{c}$ & No & $+/+/+/-/ ;$ moderate \\
\hline SOFAS & $1(74)$ & No & $\mathrm{N} / \mathrm{A}$ & No & No & Serious $^{c}$ & No & $+/+/+/-/ ;$ moderate \\
\hline YMRS & $1(74)$ & No & $\mathrm{N} / \mathrm{A}$ & No & No & Serious $^{c}$ & No & $+/+/+/-/ ;$ moderate \\
\hline Discontinuation for any reason & $1(75)$ & No & $\mathrm{N} / \mathrm{A}$ & No & No & Serious $^{\mathrm{C}}$ & No & $+/+/+/-/ ;$ moderate \\
\hline Nausea & $2(125)$ & No & No & No & No & Serious $^{c}$ & No & $+/+/+/-/ ;$ moderate \\
\hline
\end{tabular}

${ }^{a}$ GRADE Working Group grades of evidence: High quality=further research is very unlikely to change our confidence in the estimate of effect. Moderate quality=further research is likely to have an important impact on our confidence in the estimate of effect and may change the estimate. Low quality=further research is very likely to have an important impact on our confidence in the estimate of effect and is likely to change the estimate. Very low quality=we are very uncertain about the estimate.

${ }^{b}$ Meta-analytic results presented a serious inconsistency when $\mathrm{I}^{2}$ values were greater than $50 \%$ or $\mathrm{P}<0.1$ in the $Q$ statistics.

${ }^{\mathrm{c}}$ For continuous outcomes, $\mathrm{N}<400$. For dichotomous outcomes, $\mathrm{N}<300$.

Abbrevations: BDRS=Bipolar Depression Rating Scale; CGI=Clinical Global Impression; CGI-S bipolar disorder=CGI-Severity scale for bipolar disorder; CGI-S depression=CGI-Severity scale for depression; CGI-S mania=CGI-Severity scale for mania; GAF=Global Assessment of Functioning Scale; GRADE=grading of recommendations assessment, development, and evaluation; MMSE=the Mini-Mental State Examination; HAMD=Hamilton Depression Rating Scale; LIFE-RIFT=Longitudinal Interval Follow-up Evaluation-Range of Impaired Functioning Tool; MADRS=Montgomery Åsberg Depression Rating Scale; N/A=not applicable; PANSS=Positive and Negative Syndrome Scale;Q-LES-Q=Quality of Life Enjoyment and Satisfaction Questionnaire; SLICE/LIFE=Streamlined Longitudinal Interview Clinical Evaluation from the Longitudinal Interval Follow-up Evaluation; SOFAS=Social and Occupational Functioning Assessment Scale; YMRS=Young Mania Rating Scale;

This article is protected by copyright. All rights reserved 
Table 3. Primary and secondary outcomes

\begin{tabular}{|c|c|c|c|c|}
\hline Variables & Study (subjects) & SMDs/RRs $(95 \% \mathrm{Cl})$ & $\mathrm{I}^{2}(\%)$ & $\mathrm{P}$ \\
\hline \multicolumn{5}{|l|}{ Schizophrenia } \\
\hline \multicolumn{5}{|l|}{ Clinical efficacy: } \\
\hline Total psychopathology & $3(247)$ & $-0.74(-1.43,-0.06)$ & 84 & 0.03 \\
\hline Positive symptom scores & $3(247)$ & $-0.16(-0.62,0.29)$ & 66 & 0.48 \\
\hline Negative symptom scores & $3(247)$ & $-0.59(-2.00,0.10)$ & 93 & 0.08 \\
\hline General psychopathology scores (PANSS) & $3(247)$ & $-0.20(-0.62,0.21)$ & 59 & 0.34 \\
\hline \multicolumn{5}{|l|}{ Discontinuation rate: } \\
\hline Discontinuation due to any reason & $3(307)$ & $0.96(0.65,1.43)$ & 0 & 0.84 \\
\hline \multicolumn{5}{|l|}{ ADRs: } \\
\hline Drowsiness & $2(167)$ & $1.79(0.67,4.79)$ & 0 & 0.25 \\
\hline Headache & $2(186)$ & $0.92(0.49,1.72)$ & 5 & 0.78 \\
\hline Constipation & $2(186)$ & $0.83(0.48,1.45)$ & 0 & 0.51 \\
\hline Diarrhea & $2(186)$ & $1.56(0.87,2.80)$ & 0 & 0.14 \\
\hline Nausea & $2(186)$ & $1.08(0.52,2.24)$ & 29 & 0.83 \\
\hline \multicolumn{5}{|l|}{ Bipolar disorder } \\
\hline \multicolumn{5}{|l|}{ Clinical efficacy: } \\
\hline Depression scores ${ }^{a}$ & $2(124)$ & $-0.59(-1.48,0.30)$ & 83 & 0.19 \\
\hline$B D R S$ & $1(74)$ & $-0.90(-1.38,-0.42)$ & $\mathrm{N} / \mathrm{A}$ & 0.0002 \\
\hline CGI-S bipolar disorder & $1(74)$ & $-0.70(-1.17,-0.23)$ & $N / A$ & 0.003 \\
\hline
\end{tabular}

This article is protected by copyright. All rights reserved 


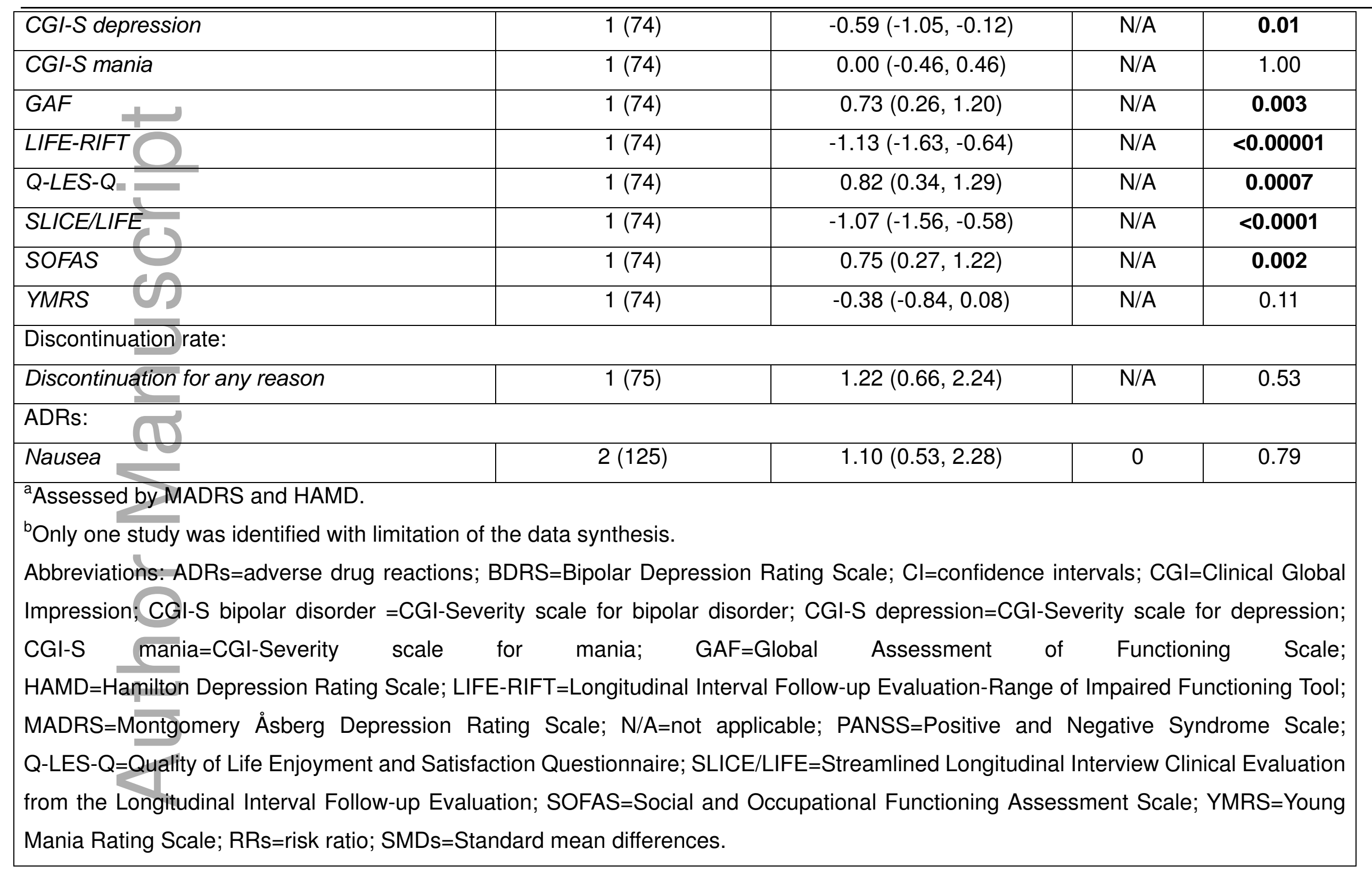

This article is protected by copyright. All rights reserved 


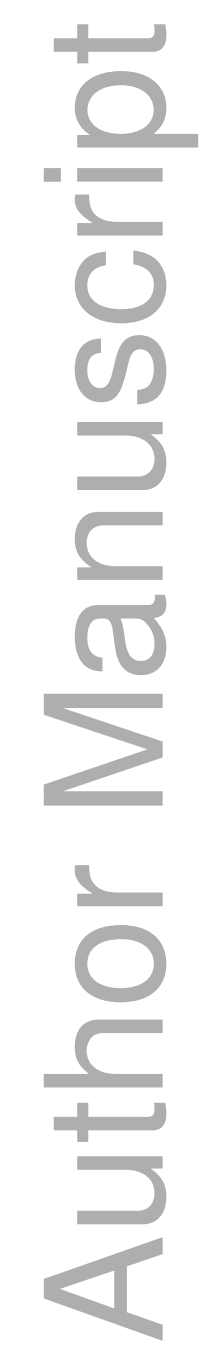

This article is protected by copyright. All rights reserved 

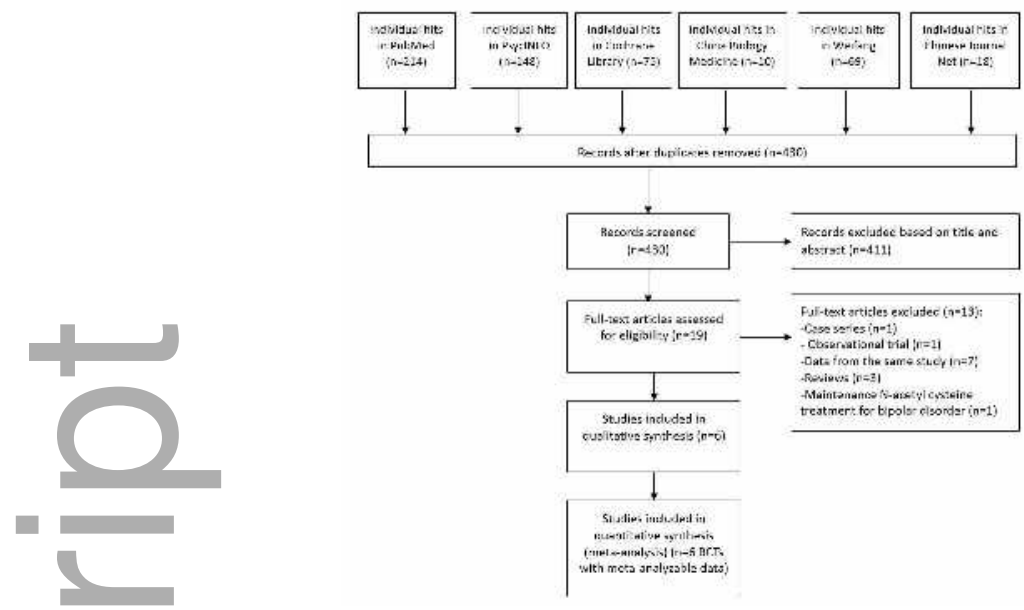

acps_12862_f1.jpg
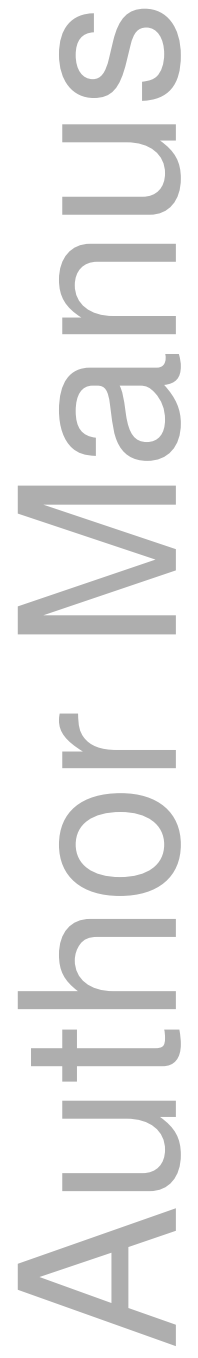

This article is protected by copyright. All rights reserved 


\section{University Library}

\section{- M M N E R VA A gateway to Melbourne's research publications}

Minerva Access is the Institutional Repository of The University of Melbourne

\section{Author/s:}

Zheng, W;Zhang, Q-E;Cai, D-B;Yang, X-H;Qiu, Y;Ungvari, GS;Ng, CH;Berk, M;Ning, YP;Xiang, Y-T

Title:

$\mathrm{N}$-acetylcysteine for major mental disorders: a systematic review and meta-analysis of randomized controlled trials

Date:

2018-05-01

Citation:

Zheng, W., Zhang, Q. -E., Cai, D. -B., Yang, X. -H., Qiu, Y., Ungvari, G. S., Ng, C. H., Berk, M., Ning, Y. -P. \& Xiang, Y. -T. (2018). N-acetylcysteine for major mental disorders: a systematic review and meta-analysis of randomized controlled trials. ACTA PSYCHIATRICA SCANDINAVICA, 137 (5), pp.391-400. https://doi.org/10.1111/acps.12862.

Persistent Link:

http://hdl.handle.net/11343/283633 